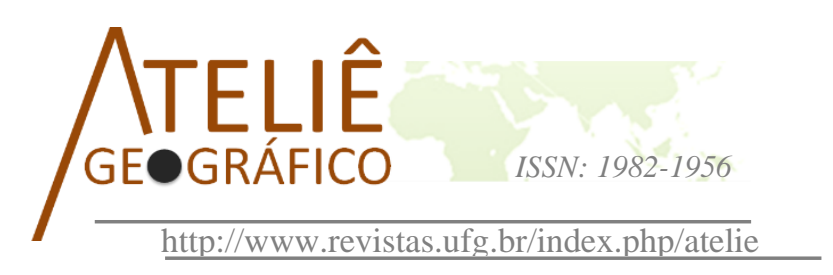

\title{
Retrospectiva de la gestión turística para el cambio de calidad en la provincia Manabí, Ecuador
}

\author{
Retrospective of tourism management for quality change in \\ the province Manabi, Ecuador
}

Retrospectiva da gestão do turismo para a mudança da
qualidade na província de Manabí, Equador

\author{
Mabel Font Aranda \\ Universidad Laica Eloy Alfaro de Manabí \\ mabel.font@uleam.edu.ec
}

Joana María Petrus Bey

Universidad de las Islas Baleares

joana.petrus@uib.es

\begin{abstract}
Resumen
El artículo tiene como objetivo analizar la retrospectiva de la gestión turística en la provincia Manabí, como punto de partida para proyectar los cambios de calidad necesarios, en un contexto de revolución tecnológica y recientemente de pausa obligada dada la pandemia Covid-19. Los preceptos teórico - metodológicos abordan la gestión turística y el sistema que la sostiene, constituido por el espacio, oferta, demanda y gestores turísticos. Se realiza la caracterización de Manabí dentro del contexto ecuatoriano y la consideración de las políticas nacionales. A través de métodos, técnicas y herramientas, como revisión bibliográfica, de documentos oficiales, encuestas, entrevistas, cartográficos, estadística descriptiva y otros, auxiliados de los softwares Excel, SPSS, ArcGIS; ocurre la reconstrucción del pasado reciente. Considerando el análisis anterior, se indican los ejes claves que inducirán a un cambio de la gestión hacia la calidad turística en la provincia Manabí. De la experiencia española vivenciada, se enfatiza en la calidad y las condiciones higiénico-sanitarias, requisitos para superar más, que la pandemia actual.
\end{abstract}

Palabras clave: Gestión turística. Calidad turística. Gestión integral. Sistema turístico.

\footnotetext{
Abstract

The article aims to analyse the retrospective of tourism management in the Manabí province, as a starting point to project the necessary quality changes, in a context of technological revolution and recently of forced pause given the Covid-19 pandemic. The theoretical-methodological precepts address tourism management and the system
} 
that supports it, consisting of space, supply, demand and tourism managers. The characterization of Manabí is carried out within the Ecuadorian context and the consideration of national policies. Through methods, techniques and tools, such as bibliographic review, official documents, surveys, interviews, cartographic, descriptive statistics and others, aided by Excel, SPSS, ArcGIS software; the reconstruction of the recent past occurs. Considering the previous analysis, the key axes that will induce a change in management towards tourism quality in the Manabí province are indicated. From the Spanish experience, emphasis is placed on quality and hygienic sanitary conditions, requirements to overcome more than the current pandemic.

Keywords: Tourism management. Tourist quality. Integral management. Tourist system.

\begin{abstract}
Resumo
$\mathrm{O}$ artigo tem como objetivo analisar a retrospectiva da gestão do turismo na província de Manabí, como ponto de partida para projetar as mudanças de qualidade necessárias, em um contexto de revolução tecnológica e recentemente de pausa forçada diante da pandemia Covid-19. Os preceitos teórico-metodológicos abordam a gestão do turismo e o sistema que a suporta, composto por espaço, oferta, demanda e gestores de turismo. A caracterização de Manabí é realizada no contexto equatoriano e na consideração das políticas nacionais. Por meio de métodos, técnicas e ferramentas, como revisão bibliográfica, documentos oficiais, pesquisas, entrevistas, cartográficos, estatísticas descritivas e outros, com auxílio dos softwares Excel, SPSS, ArcGIS; ocorre a reconstrução do passado recente. Considerando a análise anterior, são indicados os eixos-chave que irão induzir uma mudança na gestão da qualidade do turismo na província de Manabí. A partir da experiência espanhola, a ênfase é colocada na qualidade e nas condições higiênicas sanitárias, requisitos para superar mais do que a atual pandemia.
\end{abstract}

Palavras-Chave: Gerência de Turismo. Qualidade turística. Gestão integral. Sistema turístico.

\title{
Introducción
}

La incidencia en todas las esferas de la sociedad, la economía y la naturaleza de la pandemia Covid-19 ha caracterizado el mundo en el año 2020. El turismo ha sido una de las actividades económicas más afectadas, porque su vitalidad depende de los movimientos de las personas. Los diferentes tipos de transportes, y en particular el aéreo, se han visto paralizados ante las estrictas medidas de confinamiento. En este panorama, aquellos viajeros decididos a dejar su espacio habitual por las ansias de conocer, visitar a familiares y amigos, desarrollar negocios u otras motivaciones, permanecen varados. Las preguntas reiteradas son ¿cómo y cuándo las llegadas de turistas internacionales alcanzarán de nuevo los 1.500 millones (OMT, 2020, p.1) contabilizados en 2019.

La pausa obligada del turismo en el escenario actual cesará más temprano que tarde. A lo largo de la historia de la humanidad, ha estado presente el desplazamiento, aun en pandemias y pasadas éstas; con más razón en el siglo XXI, cuando millones de familias están separadas porque viven en contextos geográficos distantes, por posibilidades de negocios gestados fuera de donde se habita, o la simple necesidad de sentir una nueva experiencia. Si bien cautelosas, las personas volverán a viajar, ahora con más exigencias higiénicas, pero con iguales motivaciones y deseos. Es cierto que 
nuevas medidas ya son planteadas para recuperar lo que se había alcanzado; sin embargo, se requiere reconocer qué bueno ya se hacía y qué no: que se exija replantear los estilos de gestión, no significa partir de cero.

El sistema turístico está conformado por cuatro componentes principales: la demanda, la oferta, el espacio turístico y los operadores (SANCHO, 1998, p.47). El enfoque de la gestión del destino considera quién o qué se gestiona, dónde se encuentran las prioridades de gestión y dónde se pueden encontrar soluciones (PEARCE, 2014, p.141). En la gestión, la satisfacción a la heterogeneidad de visitantes se deriva de la interacción del cliente con la empresa y la comunidad, la co-creación de valor, la construcción de una mejor experiencia (DOLAN \& KEMPER, 2019, p.36; PADDISON, \& BIGGINS, 2017, p.2; GONZÁLEZ-MANSILLA et al. 2019, p.51). La calidad del servicio es un factor determinante de la satisfacción del cliente (PARASURAMAN, et al. 1988; SU, et al. 2016, p.83). A nivel del territorio y del destino turístico, la calidad se complejiza, ya que además de cómo se manifieste el sector empresarial de forma individual o colectiva, se agrega el sentir de la comunidad, el estado del medio ambiente y de los atractivos turísticos que soportan las ofertas y actividades.

En la gestión turística, favorece el desarrollo de nuevos esquemas, la existencia de un marco integral y estable que agrupe todas las políticas sectoriales afectadas y permita el desarrollo de directrices y líneas de actuación (PULIDO-FERNÁNDEZ Y LÓPEZ-SÁNCHEZ 2016, p.172). La administración debe realizar una gestión social continuada de la convivencia entre turismo y residentes, con esquemas de participación social en las decisiones (DURO Y RODRÍGUEZ, 2015, p.533). Se destacan como principal entidad, las organizaciones de gestión de destinos (OGD) integrales; forman parte de ellas diversas autoridades, agentes y profesionales, y facilitan las alianzas dentro del sector turístico con miras a un proyecto colectivo para el destino (OMT 2019, p.12).

Existen brechas en la gestión de la calidad turística (ÁLVAREZ-GARCÍA, DEL RÍO-RAMA, DURÁN Y URBANO-ORGAZ, 2017, p.12), que no consiste únicamente en producir "cero defectos" y cumplir los requisitos básicos, sino que implica un plus de atención, innovación y excelencia y la participación de entidades, tanto del sector público como del privado, comprometidas y coordinadas (OMT, 2015, p.14), pues el objetivo de las OGD no es otro que lograr una estructura formal de gestión y planificación de un destino turístico (SWISSCONTACT, 2014). Es referente entre las OGD, el Sistema Integral de Calidad Turística Española en Destinos (SICTED) y el enfoque de los destinos turísticos inteligentes o smart destination centrados en gestionar íntegramente la calidad para todos los servicios en un destino turístico (SECRETARÍA DE ESTADO DE TURISMO, 2019, p.3,5; IVARS-BAIDAL y VERA REBOLLO 2019, p.10).

Basado en el concepto de itinerario de consumidor, con una atención equilibrada en el destino turístico, las interrogantes a las que habría que dar respuesta en SICTED son: qué (enfoque, metodología), quiénes (gestores, empresas, voluntarios), cómo (organizado por procesos, integrado y participativo), para qué (impulsor de otros productos tecnológicos, orientado a resultados, calidad, experiencias, satisfacción del turista) (SECRETARÍA DE ESTADO DE TURISMO, 2019, p.3). Las buenas prácticas 
registradas en manuales tienen dos funciones: una individual, servir de instrumento a las empresas para instaurar un sistema de gestión de la calidad; y una colectiva, que es proporcionar indicadores para el plan de mejora del destino, según el grado de cumplimiento de éstos (CORRAL-MARFIL, 2012, p.9; MELLÉN MADRUGA y SOLER REGLÍ, 2018, p.13).

En relación con Manabí (Ecuador), cabe reconocer el potencial para el desarrollo turístico que tiene esta provincia costera y la puesta en valor de recursos y atractivos, así como determinados servicios básicos para la estancia y el disfrute de que dispone. El artículo tiene como objetivo analizar la retrospectiva de la gestión turística en la provincia Manabí como punto de partida para proyectar los cambios de calidad necesarios, en un contexto de permanente revolución tecnológica y, recientemente, de pausa obligada dada la pandemia Covid-19.

\section{Consideraciones metodológicas sobre retrospectiva y cambio de calidad en turismo}

La forma más básica de retrospectiva responde a las siguientes preguntas: ¿Qué hicimos bien? ¿Qué hicimos mal? ¿Qué vamos a hacer distinto la próxima vez para mejorar? La sistematización metodológica parte de los preceptos teóricos referidos en la introducción. La tabla 1 contiene la secuencia de pasos metodológicos y los métodos, técnicas y herramientas utilizados. El planteamiento de recomendaciones para asumir la realidad actual tiene como base la retrospectiva de gestión turística y funcionamiento del sistema.

Tabla 1: Diseño metodológico general

\begin{tabular}{|c|c|c|}
\hline Pasos & $\begin{array}{c}\text { Métodos técnicas y } \\
\text { herramientas }\end{array}$ & Principales resultados \\
\hline $\begin{array}{l}\text { 1- Interpretación de las } \\
\text { políticas turísticas de la } \\
\text { República del Ecuador. }\end{array}$ & $\begin{array}{c}\text { Análisis y síntesis, } \\
\text { comparación, } \\
\text { Revisión de documentos } \\
\text { oficiales, } \\
\text { Tabla resumen }\end{array}$ & $\begin{array}{l}\text { Declaraciones de } \\
\text { intenciones a nivel de país } \\
\text { sobre el turismo. } \\
\text { Disponibilidad de } \\
\text { información para la gestión } \\
\text { turística. }\end{array}$ \\
\hline $\begin{array}{c}\text { 2- Examen retrospectivo } \\
\text { del sistema turístico de } \\
\text { Manabí: } \\
\text { Espacio Turístico, } \\
\text { Oferta, } \\
\text { Demanda, } \\
\text { Operadores. }\end{array}$ & $\begin{array}{l}\text { Revisión bibliográfica, } \\
\text { Análisis y síntesis, tablas, } \\
\text { comparación, } \\
\text { cartográficos, entrevistas, } \\
\text { encuestas, muestreo, } \\
\text { diagramas, estadística } \\
\text { descriptiva, } \\
\text { SPSS, Excel, ArcGIS } 10.4\end{array}$ & $\begin{array}{c}\text { Descripción del estado } \\
\text { actual del sistema turístico } \\
\text { de Manabí. } \\
\text { Identificación de fortalezas } \\
\text { y debilidades para la } \\
\text { gestión integrada e } \\
\text { inteligente }\end{array}$ \\
\hline 3- Ejes claves de cambio. & $\begin{array}{l}\text { Lluvia de ideas, criterio de } \\
\text { especialistas, diagrama de } \\
\text { afinidade }\end{array}$ & Pautas a seguir. \\
\hline
\end{tabular}

Fuente: Elaboración propia. 
La revisión de documentos oficiales clave del país sustenta la gestión, visualiza las oportunidades para el desarrollo del turismo en el territorio y sugiere cómo derivar las acciones acordes con las políticas nacionales. Los posicionamientos políticos respecto el turismo en la República del Ecuador, se expresan en: la Constitución de la República del Ecuador (2008), la Ley de Turismo (2002), el Plan Nacional de Desarrollo (2017- 2021) y los Planes de Desarrollo del Turismo (PLANDETUR 2020 y PLANDETUR 2030). Se seleccionan ejes, objetivos y la implicación que éstos tienen en la gestión turística.

La visión geográfica y turística del Ecuador refleja el análisis, síntesis y comparación de información estadística, cartográfica y literal procedente de los documentos referidos. También se manejan fuentes disponibles en sitios web del Instituto Nacional de Estadística y Censo (INEC, 2019), Secretaría Técnica Planifica Ecuador, antes Secretaría Nacional de Planificación y Desarrollo (SENPLADES), Ministerio de Ambiente, Ministerio de Turismo.

En particular, del Instituto Geográfico Militar (IGM) se consultaron mapas oficiales y se recurrió a las capas disponibles para la elaboración de otros mapas mediante el software ArcMap de ArcGIS, principalmente a nivel provincial y cantonal. La interpretación y contraste de datos proporciona la posibilidad de reconfigurar la información acerca de los espacios turísticos de Manabí o de representar cartográficamente información levantada en el terreno.

La oferta turística se analiza a partir de bases de datos del MINTUR (2018a, 2019a, 2020). De ellas se extrajo la información específica de la provincia. La estadística descriptiva expresada en gráficos y mapas favorece la comprensión del estatus de este componente respecto entidades turísticas, su distribución y características principales.

Para el estudio de la demanda se emplea un cuestionario de encuesta resultado parcial del proyecto Observatorio Turístico de Manabí (FONT Y ÁLVARO, 2019). El instrumento se estructura en cuatro secciones: 1-Perfil del viajero, 2- Del viaje, 3- Gasto, 4.-Destinos, motivos, experiencias, que conforman un total de 21 preguntas. Las preguntas que miden satisfacción utilizan una escala ordinal de Likert. Se asume como población el total de visitantes llegados a los cantones considerados turísticos de la provincia Manabí, Ecuador (MINTUR, 2018a), durante julio de 2017. El muestreo probabilístico diferenció turistas nacionales y extranjeros, considerando un nivel de confianza del $95 \%$, un error muestral del $5 \%$ y una probabilidad de 0,5 . El cuestionario se aplicó en julio de 2018, la información fue recogida en el terreno seleccionando determinados lugares donde habitualmente se concentran los turistas: playas, terminales, centro de ciudad, parques recreacionales, comercios, hoteles, restaurantes. El procesamiento de los datos se realizó con SPSS versión 25. Con estudiantes de octavo semestre de Turismo se encuestaron 1.375 turistas nacionales y 344 turistas extranjeros.

La información respecto los operadores turísticos se obtuvo de entrevistar al máximo representante del MINTUR en la Zona 4 (provincias de Manabí y Santo Domingo de los Tsáchilas) y a 40 gestores de los cantones turísticos de la provincia de 
Manabí, utilizando el contingente estudiantil del primer semestre de la carrera Turismo. Las interrogantes orientan la constatación de las falencias de la actividad turística en la provincia y la identificación de propuestas de mitigación. Además, se interpretan datos estadísticos del MINTUR (2018a, 2019a, 2020) sobre cantidad, género, ocupación y distribución por cantones de los empleados en turismo.

\section{Contexto político del Ecuador para la gestión turística en Manabí}

La Constitución declara las pautas que rigen en el país y que los implicados en turismo deben asumir. Aspecto distintivo es el Derecho de la Naturaleza, junto a otros como Planificación participativa para el desarrollo y Ciencia, tecnología, innovación y saberes ancestrales; éstos deberán considerarse con mayor atención para la gestión integral e inteligente de los destinos turísticos.

La Ley 97 de Turismo (2012) y su Reglamento (art. 8,11,15,19, 45, 52), rigen el marco legal para la actividad y los involucrados; se reitera de forma explícita la aplicación de las normas técnicas y de calidad vigentes, el rol de la empresa privada en la creación de negocios y la función pública en el control. Igualmente, se insta al establecimiento de políticas en los planes de desarrollo de las empresas y el destino.

El Plan Nacional de Desarrollo (2017-2021) aborda varios aspectos dirigidos a potenciar y estimular el sistema turístico a través de tres ejes y nueve objetivos. En primer lugar, el Plan plantea que "el principal reto es el fortalecimiento de la coordinación entre el sector público y privado, para diversificar y mejorar la calidad y la competitividad de los servicios turísticos". La declaración explícita del rol del turismo está recogida en el Eje 3. Más sociedad, mejor Estado; y en el Objetivo 9, donde el énfasis está en el turismo comunitario sostenible, el desarrollo de nuevas ofertas a partir de la diversidad natural y cultural del país (SENPLADES, 2017). En cuanto a la gestión, se insta a los vínculos políticos, sociales, económicos, turísticos, ambientales, académicos y culturales, y las líneas de cooperación para la investigación, innovación y transferencia tecnológica.

La comparación entre ejes estratégicos y metas de los planes de desarrollo turísticos 2020 y 2030, permite visualizar la evolución y continuidad de ejes como Marketing y promoción, y metas que implican unión de esfuerzos, donde se incorpora la academia. Distingue al plan actual, el interés por la calidad, la innovación, las tecnologías, la seguridad y la mejora continua, demostrando una evolución en la planificación (figura 1). 

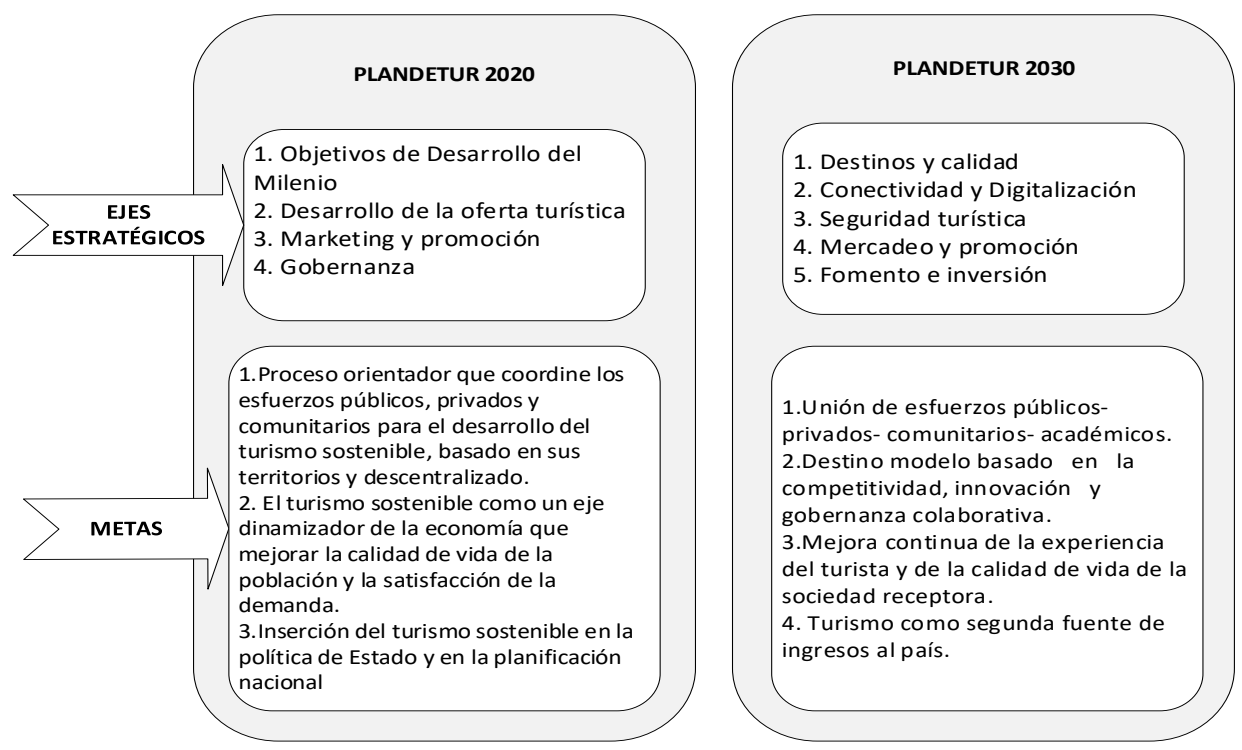

Figura 1: Comparación ejes y metas de los planes de desarrollo turísticos.

Fuente. Elaboración propia a partir de MINTUR, 2007 y MINTUR, 2019.

Desde el 18 de julio de 2018, Ecuador forma parte de la Alianza para el Gobierno Abierto. Esta es una iniciativa internacional que promueve la transparencia, la lucha contra la corrupción, la participación, la gobernanza, el libre acceso a la información pública y el uso de las nuevas tecnologías. El Plan de Acción Nacional de Gobierno Abierto 2019-2021 (Gobierno de Ecuador, 2019), es una estrategia que puede favorecer a mitigar la dispersión de datos que genera cada ministerio y que el Sistema Nacional de Información, no siempre logra aunar; hay restricciones, se modifica la información en función de determinados intereses o está desactualizada.

\section{Espacio geográfico para el espacio turístico}

Manabí tiene una extensión de $19.498,80 \mathrm{~km}^{2}$, se ubica hacia el centro oeste del país, colindando con el Océano Pacífico, donde existe una longitud de costas aproximada de 370,53 km (Secretaria Técnica del Mar, 2014 citado por SENPLADES, 2015, p.67). Estos aspectos, la posición equidistante a las provincias Pichincha y Guayas (núcleos socioeconómicos), el estar atravesada por principales arterias viales de transportación y la línea equinoccial, determinan una ubicación geográfica privilegiada.

La litología, en mayor parte, corresponde a rocas sedimentarias: areniscas, arenas, arcillas, lutitas, calizas en las llanuras y cerros; en la cordillera costanera afloran lavas, tobas, brechas de origen volcánico, donde se encuentran las principales alturas, hasta cerca de 860 m s.n.m. El clima varía entre subtropical seco y tropical húmedo de 
noreste a suroeste, por lo que disminuyen las temperaturas (media anual entre $22-24$ $\left.{ }^{0} \mathrm{C}\right)$ y las precipitaciones de $\mathrm{NE}$ a SW. En correspondencia, se desarrolla la red hidrográfica que baña el territorio, más intensa del centro hacia el norte. Este escenario, es óptimo para el desarrollo del turismo de sol y playa, (modalidad que distingue la provincia), pero también para el turismo de naturaleza y rural, excelente alternativa en las condiciones actuales (figura 2).

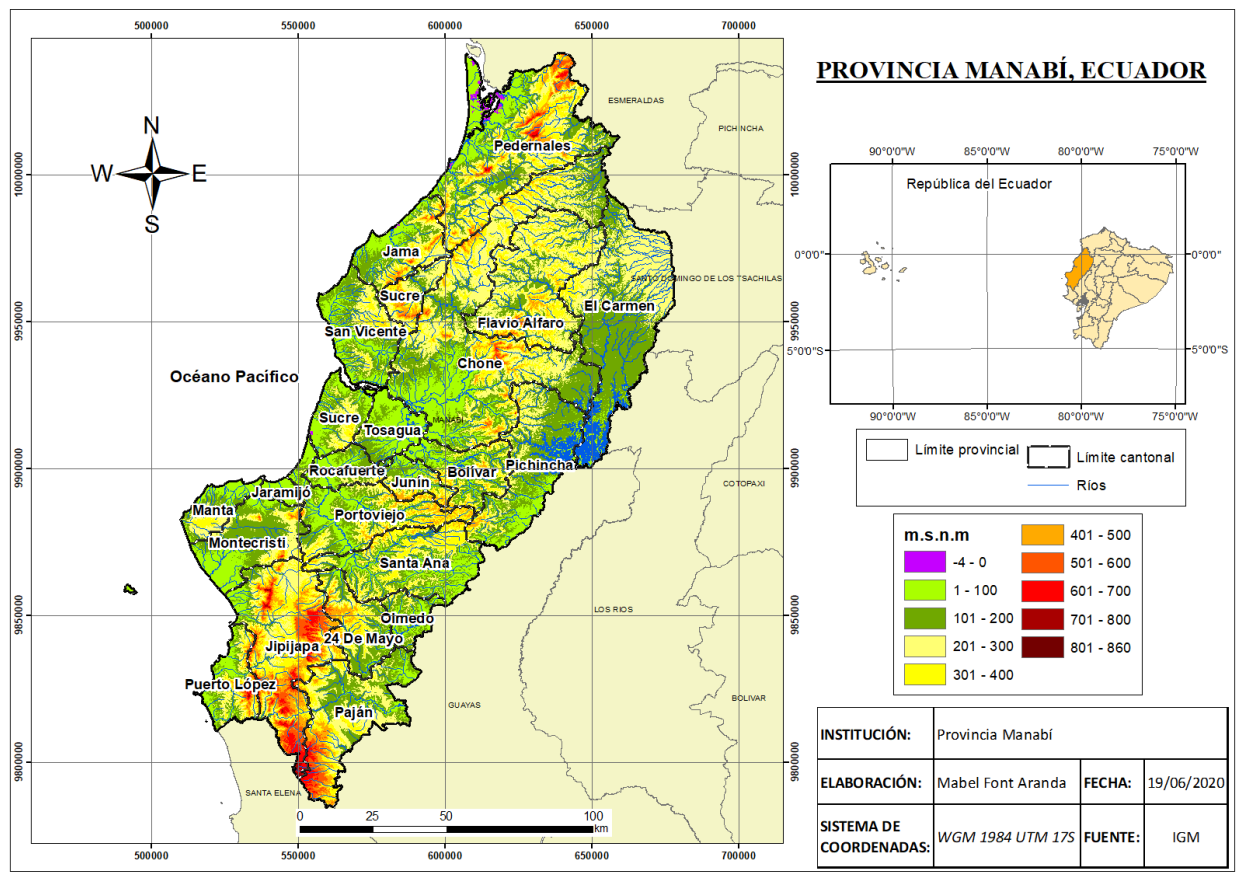

Figura 2: Mapa de la provincia Manabí.

Fuente. Elaboración propia a partir de capas de IGM, 2016. Imagen satelitar Aster GDEM U.S. Department of the Interior | U.S. Geological Survey

Cinco áreas protegidas abarcan parte de la provincia (norte a sur): Refugio de Vida Silvestre Manglares El Estuario de Río Muisne, Reserva Ecológica Mache Chindul, Refugio de Vida Silvestre Islas Corazón y Fragatas, Refugio de Vida Silvestre Marino Costera Pacoche, Parque Nacional Machalilla (MINISTERIO DE AMBIENTE Y AGUA, 2020). Además, en los espacios con alturas superiores a los 400 m s.n.m, existen bosques protectores como en las colinas circundantes a Portoviejo, Montecristi, Cordillera Chongón Colonche (al sur de la provincia) y al norte, en Pedernales (Pata de Pájaro y Mache Chindul). También son representativos los bosques, en cuencas y subcuencas como el Daule Peripa (este), Carrizal Chone (centro), ríos Paján, Cantagallos y Jipijapa al sur, y los sistemas de manglar en costas bajas y/o estuarios de los ríos. De acuerdo con la zonificación funcional de los espacios, se desarrollan actividades 
turísticas como el senderismo, la observación de la flora, la fauna y los paisajes, escaladas, cicloturismo, entre otras.

Desde el punto de vista socioeconómico, la población proyectada en 2018, a partir del censo de 2010 fue de 1'537.090, distribuida en 22 cantones. Existen abundantes yacimientos arqueológicos de culturas como Machalilla, Jama Coaque y Manteña. La población esencialmente rural, se dedica a la producción agropecuaria (ganado, cacao, café, arroz, frutas cítricas), también se destaca la actividad pesquera, en particular del atún. La ubicación geográfica de la provincia beneficia la actividad portuaria y pesquera, destacándose el puerto comercial de Manta y los artesanales de San Mateo y Jaramijó, también la facilidad pesquera en Cojimíes. La variedad de tipos y medios de transporte, favorecen la accesibilidad, a través de la ruta Spondylus, y el aeropuerto Eloy Alfaro, en Manta, por citar dos ejemplos. Se destaca el Patrimonio Cultural Inmaterial de la Humanidad "Tejido del Sombrero de Paja Toquilla".

En términos productivos (SENPLADES, 2017, p.115), la provincia de Manabí posee enclaves industriales o turísticos puntuales, los cuales modifican de a poco la dinámica económica y territorial, como lo es el procesamiento de productos del mar en Manta y el turismo en las costas de Manabí. En la mayor superficie del territorio provincial existe un "Bajo desarrollo primario de mayor diversificación con puntales productivos y especial importancia de los cultivos de cacao y de maíz”.

Los problemas prioritarios relacionados con la gestión turística en la provincia de Manabí se representan en la figura 3 el diagrama causa efecto se elabora a partir de PROAÑO y RAMÍREZ, (2017, p.71); SENPLADES, (2019, p.42) con base en criterios de documentos oficiales y actores clave).

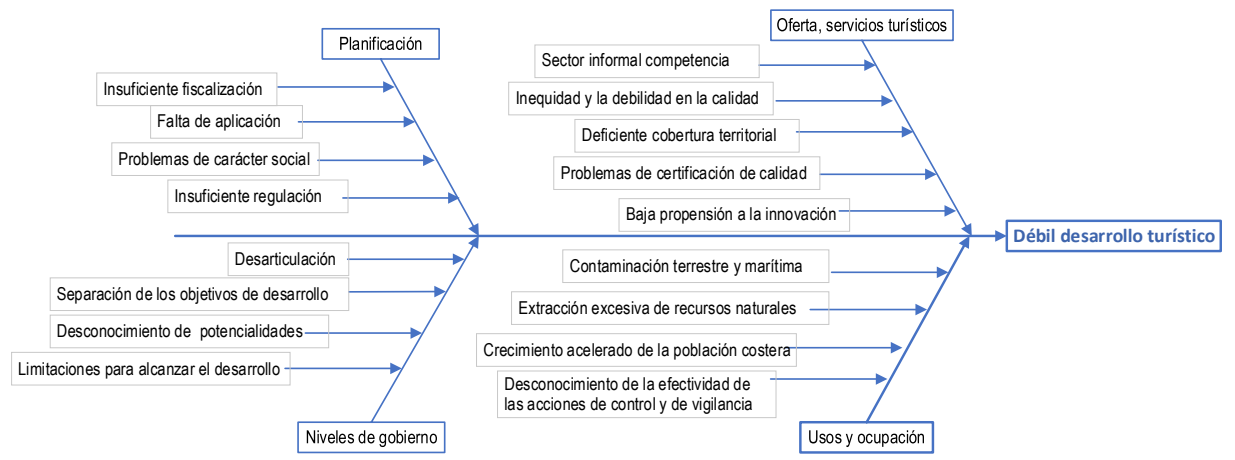

Figura 3: Diagrama causa efecto sobre gestión turística en la provincia Manabí.

Fuente: Elaboración propia a partir de PROAÑO y RAMÍREZ, (2017, p.71); SENPLADES, (2019, p.42)

Las necesidades principales relacionadas con la gestión turística según SENPLADES (2019, p. 42) son: Fortalecer el talento humano de los GAD en herramientas e instrumentos para la planificación, ordenamiento y gestión del territorio. La principal prioridad (Ponderación Muy Alto) de los GAD en la Zona 4 es el 
componente Político "Capacidades del GAD para la gestión del territorio". Si se actúa sobre esta necesidad y prioridad, se contribuye a la resolución de los problemas plasmados en el diagrama de causa efecto y se generará un aumento en el desarrollo turístico provincial. Se impone una gestión integrada e inteligente de destinos turísticos que acoja todos los aspectos aquí señalados, incidiendo en la mejora de la calidad.

\section{Oferta turística de Manabí}

La oferta turística de Manabí guarda estrecha relación con las características geográficas predominantes en el territorio y las formas de asimilación del espacio turístico. En la franja costera manabita se concentra el predominio de las ofertas (figura 4).

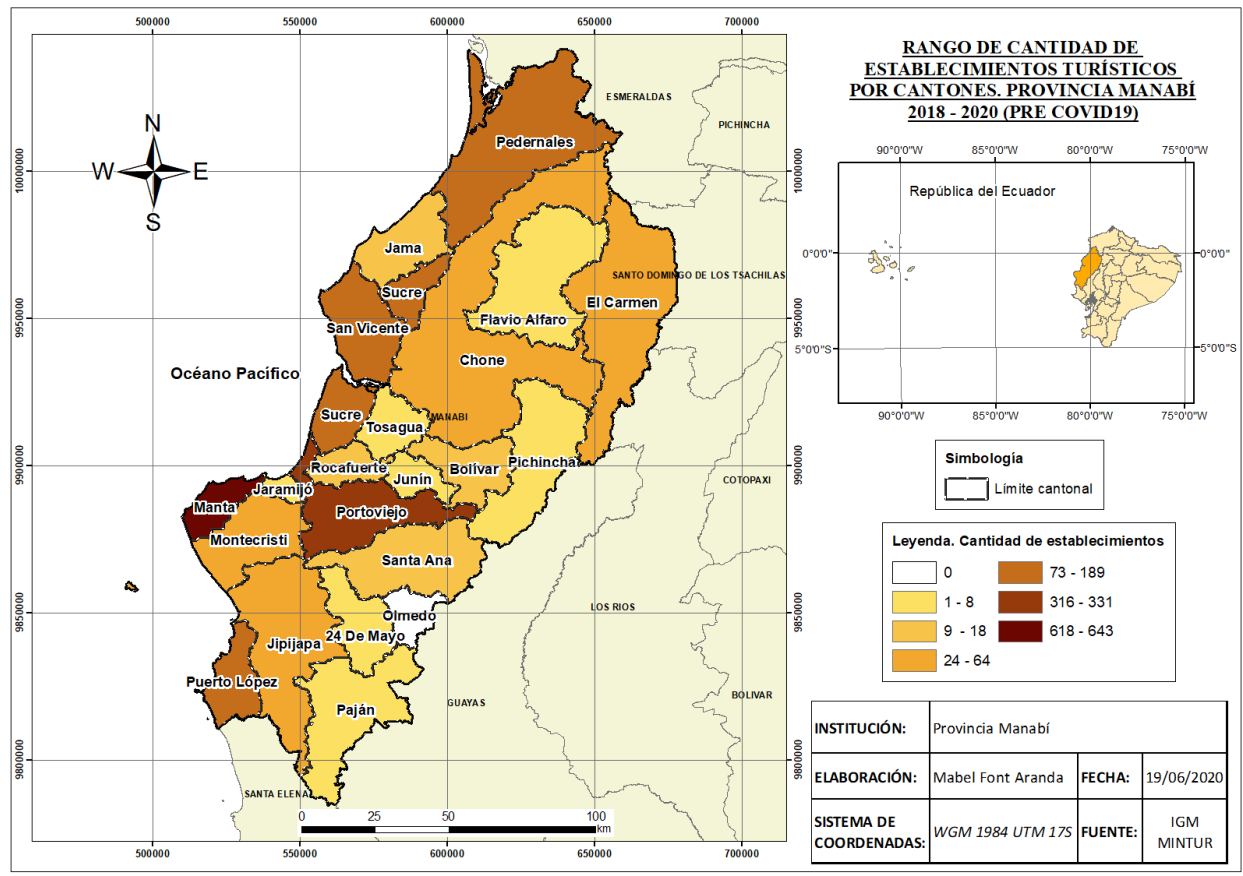

Figura 4: Establecimientos Turísticos de Manabí.

Fuente: Elaboración propia a partir de catastros MINTUR, 2018a, 2019, 2020 pre Covid19.

A nivel provincial el tipo de establecimiento turístico predominante es Alimentos y Bebidas (figura 5 y 6), la provincia se distingue por la diversidad de platos típicos, asociados a la pesca de variadas especies, con las que se elaboran los viches y ceviches. Las numerosas ofertas a base de maní y plátano distinguen la gastronomía manabita a nivel nacional y mundial. Otros preparados, teniendo como materia prima el maíz y la yuca, marcan la diferencia del menú provincial. La mayoría de estos establecimientos son micro y pequeñas empresas $(86 \%)$, frecuentemente de carácter 
familiar. Este último rasgo es válido para otros tipos de empresas turísticas, excepto las de alojamiento, que llegan a ser medianas empresas o forman parte de grandes empresas de firmas nacionales.

Las entidades de Intermediación y Operadoras representan el 11\%, del que sólo la mitad se dedica a la intermediación; las operadoras diseñan recorridos y paquetes que incluye la visita a los atractivos turísticos naturales o culturales como museos, casi siempre con componentes arqueológicos.

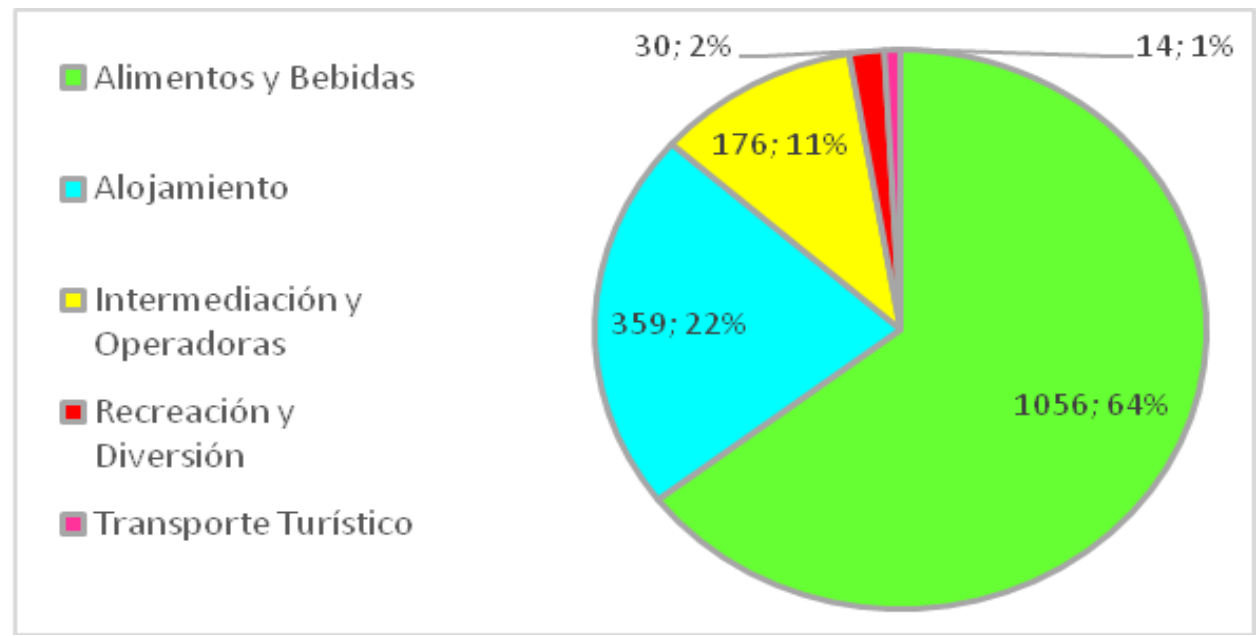

Figura 5: Tipos de establecimientos, Manabí (MINTUR, 2019a)

La distribución por cantones de la estructura en cuanto a tipos de establecimientos muestra que, aunque predomina el mismo comportamiento global, existe diferenciación territorial (figura 6).

Los cantones del centro norte poseen menor variedad, mientras que los cantones del centro sur concentran los establecimientos de Recreación y Diversión. Los asentamientos principales de estos territorios se ubican distantes de la costa, lo que estimula la creación de otras alternativas para pasar el tiempo libre. Coincide aquí, con la presencia de entidades de intermediación y operadoras. Las empresas transportistas son limitadas y tienen carácter inter cantonal esencialmente. 


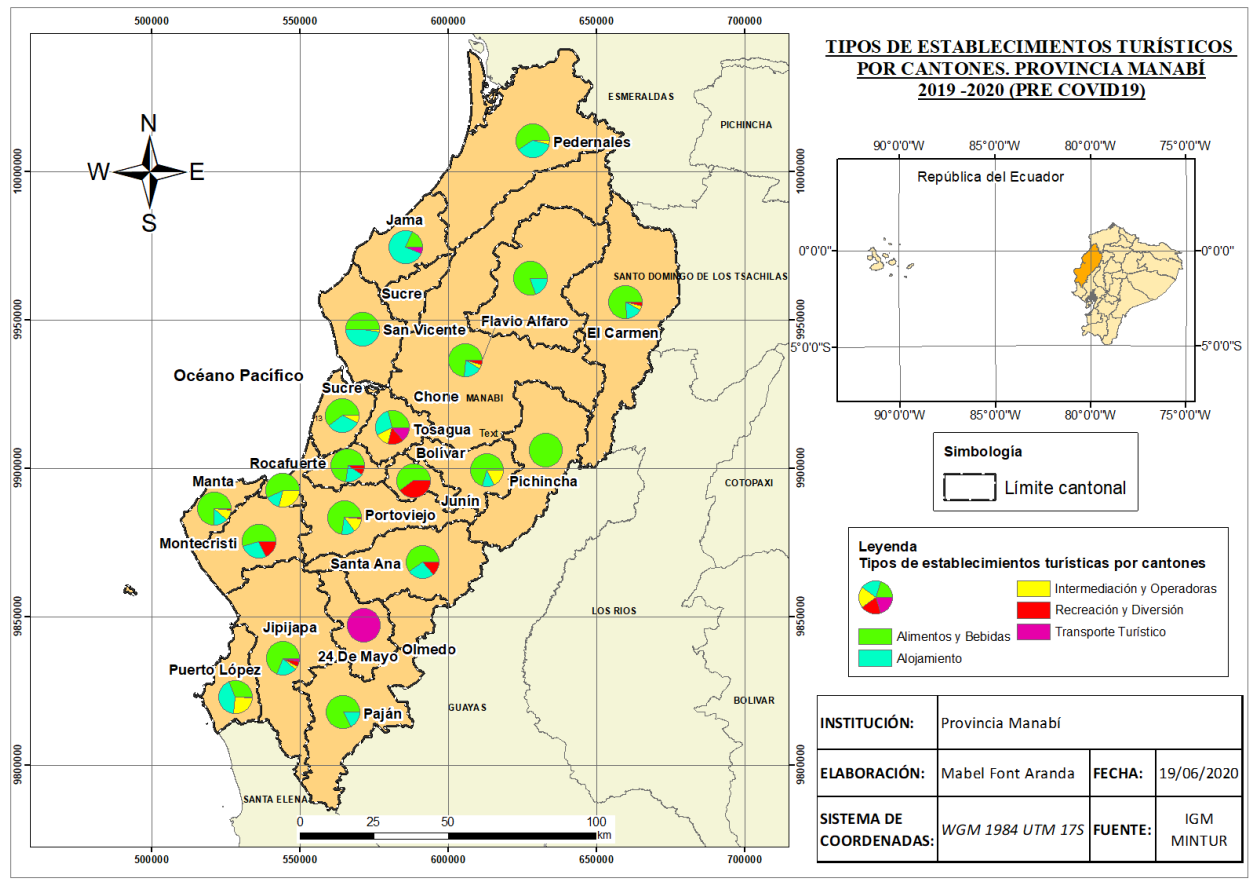

Figura 6: Tipos de establecimientos turísticos por cantones.

Fuente: Elaboración propia a partir de capas IGM y catastro MINTUR, 2019 - 2020 (pre Covid19)

De los mapas, figuras 2, 4 y 6, así como del inventario de atractivos turísticos 2019, se sintetiza:

1-Concentración de atractivos y ofertas turísticas en el litoral 77\%.

2-Pricipales componentes geográficos que sostienen la oferta turística: relieve (playas y cerros), hidrografía (ríos, presas, pozos azufrados, humedales), flora y fauna (cinco áreas protegidas), población - cultura (arqueología, etnografía, gastronomía, patrimonio), comercio (artesanías, gastronómico, sombrero fino de paja toquilla, productos industriales).

3- Principales modalidades: sol y playa, naturaleza, turismo cultural, eventos, turismo rural, negocios.

4- Principales ofertas y actividades: Actividades náuticas, visita a museos, recorridos por sitios arqueológicos, observación de la flora y la fauna, recorridos por circuitos, eventos diversos. alojamiento.

5- Predominio de establecimientos turísticos de alimentos y bebidas y 
Existe divergencia de información, en especial cuando se tratan los atractivos turísticos, pues cada dirección, a cada nivel, maneja una información diferente. Ejemplo de lo antes planteado es que en el año 2019 la Dirección Zonal 4, que incluye la provincia Manabí, contabilizó 13 atractivos turísticos en Puerto López, mientras el Gobierno cantonal registró 36, variando en más del doble. Lo anterior evidencia deficiencia en el registro y manejo de información para la gestión (Dirección Zonal 4, 2019 y Gobierno Autónomo Descentralizado de Puerto López, 2019).

\section{Demanda turística en Manabí}

Los cantones identificados como turísticos corresponden a aquellos que tienen mayor cantidad de ofertas y variedad de espacios que atraen visitantes (según datos del MINTUR, 2018a, 2019a, 2020) y en correspondencia se incrementa el número de operadores turísticos. Los cantones destacados en este ámbito son: Puerto López, Manta, Portoviejo, Sucre, San Vicente. La figura 7 destaca los cantones que cumplen con la descripción anterior y donde se encuestaron turistas en 2018.

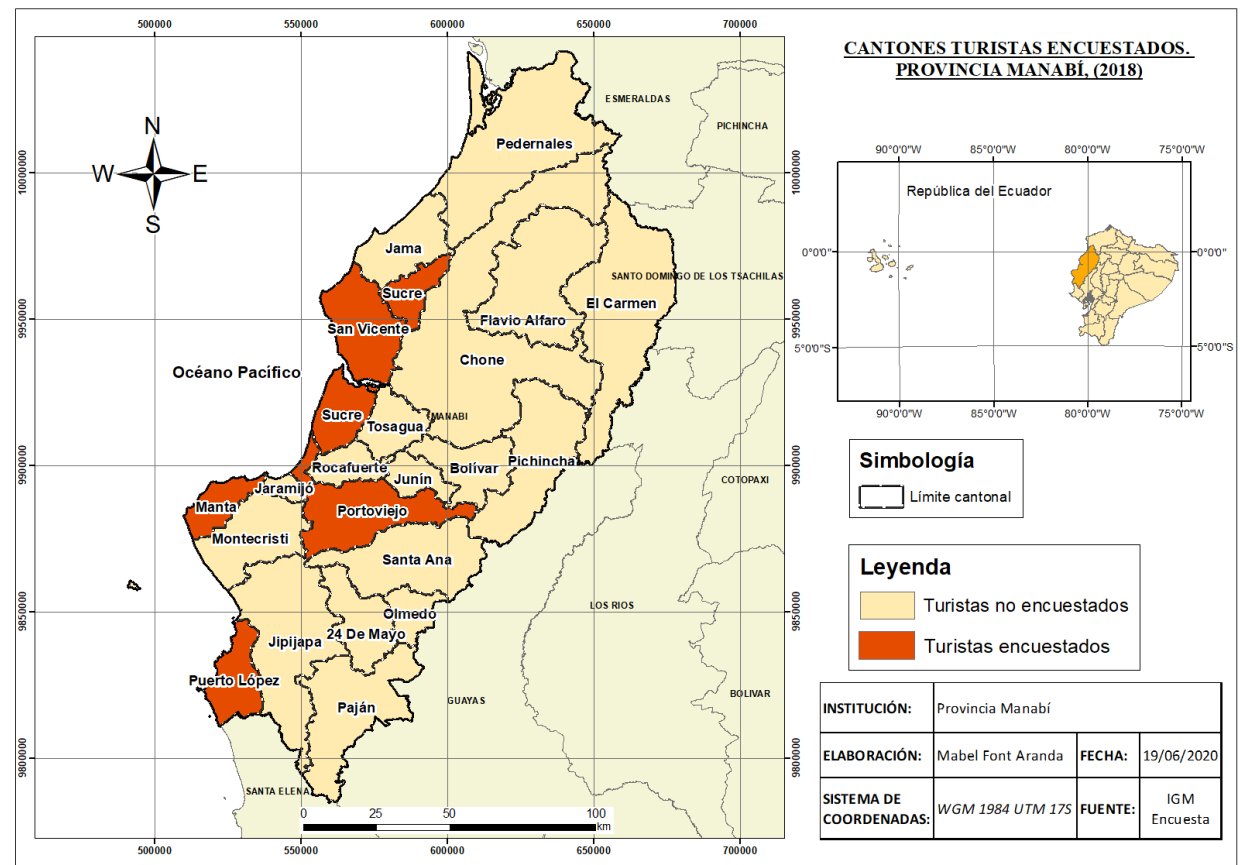

Figura 7: Cantones turistas encuestados, 2018.

Fuente: Elaboración propia a partir de encuesta.

Acerca del perfil del viajero, los principales grupos etarios encuestados corresponden a adultos entre 26 y 52 años, similar comportamiento a nivel nacional (MINTUR, 2018). El 66\% de los turistas que visitan Manabí son de nacionalidad ecuatoriana y un $34 \%$ extranjeros (figura 8). Del total de extranjeros, el 36,7\% es estadounidense y el 14\%, colombiano. 


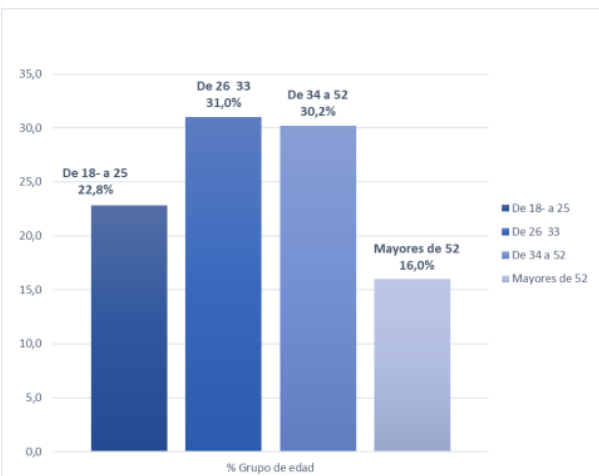

Encuestados por grupo de edad.

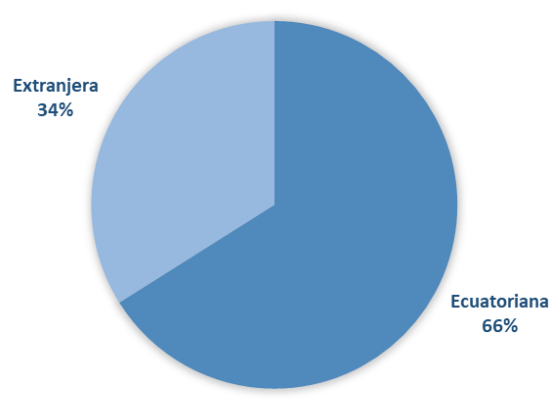

Proporción de encuestados.

Figura 8: Perfil del viajero encuestado (2018).

Fuente. Elaboración propia.

La encuesta según muestreo refleja que Puerto López y Manta reúnen el 73\% del turismo internacional que visita Manabí; San Vicente, el 19\%, mientras que el 8\% restante se reparte entre Portoviejo $(5,8 \%)$ y Sucre. Los residentes en Ecuador, en cambio, visitan mayoritariamente Portoviejo (39\%), Manta (30\%) y Puerto López (27,3\%). Esos tres cantones suman el 96,3\% del turismo interno que visita Manabí.

Con relación al viaje (figura 9) los visitantes llegan a Manabí, proporcionalmente en transporte público (42\%) y particular (45\%), un menor porcentaje llega en avión (12\%). Se evidencia repetición y motivación por regresar al destino, ya que el 37\% de los visitantes que llegan a Manabí ya han estado antes. Aproximadamente tres cuartos de los encuestados planificaron el viaje en "menos de una semana" $(25 \%)$, "una semana" (28\%) o "un mes" (27\%).

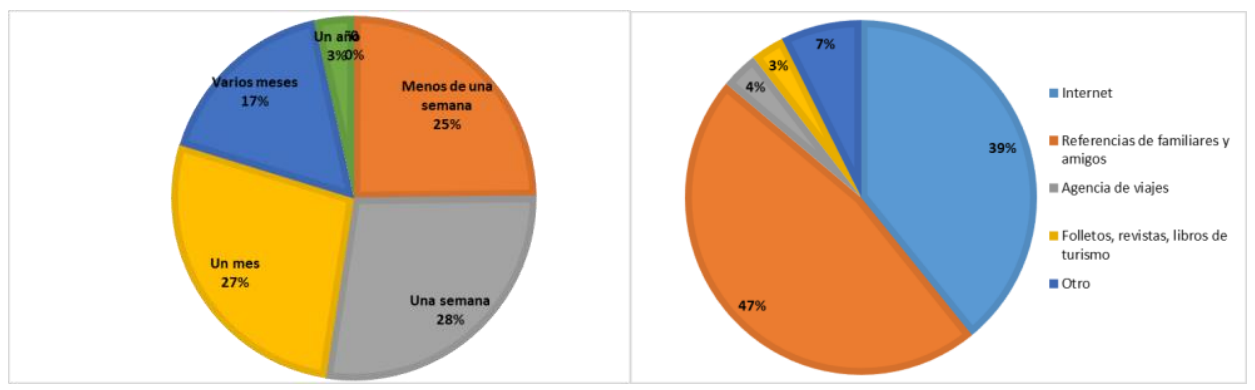

Tiempo de planificación del viaje

Medios de planificación

Figura 9: Aspectos distintivos de la planificación del viaje (2018).

Fuente. Elaboración propia.

La referencia a familiares y amigos es el principal medio de planificación del viaje (47\%). A tono con el auge de las tecnologías, Internet es el segundo medio de 
planificación (39\%). Las personas adultas son más conservadoras y este es el grupo de edad que más vista Manabí.

Respecto el gasto, casi tres cuartas partes de los encuestados empleó menos de 200 dólares diarios $(87,7 \%)$ y la mayoría $(40 \%)$ utilizó menos de 50 dólares diarios. La figura 10 muestra las proporciones.

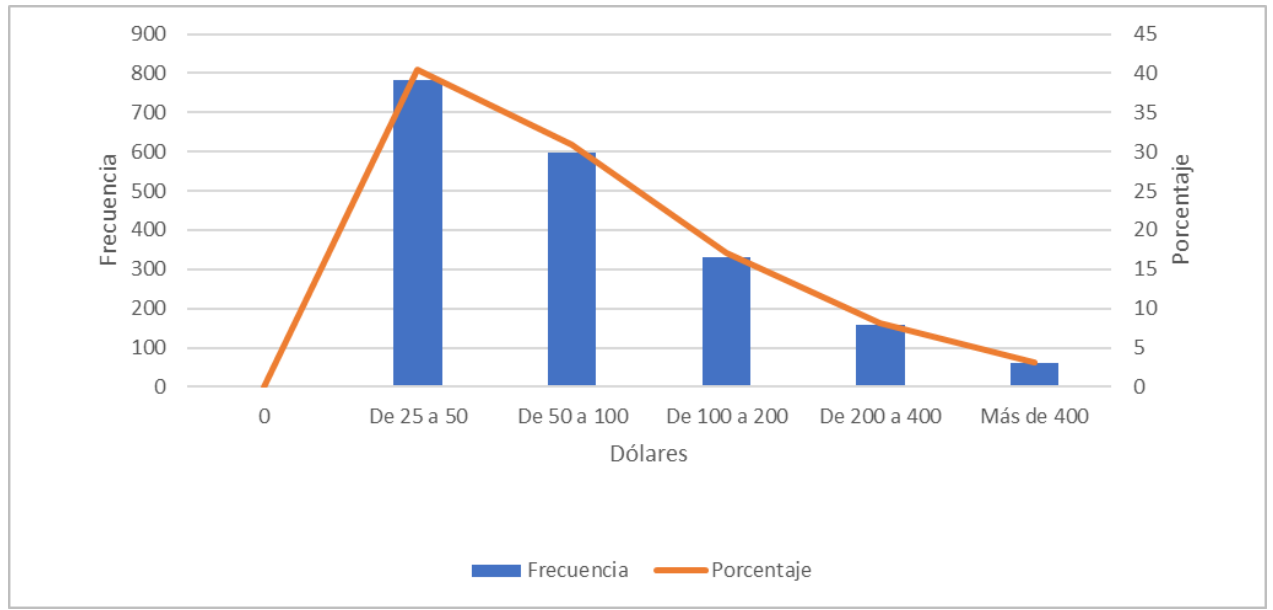

Figura 10: Gasto diario (2018).

Fuente. Elaboración propia.

El predominio de las valoraciones acerca de los precios de los diferentes servicios y ofertas han sido calificadas de forma intermedia o relativamente baratos, de acuerdo con la figura 11 .

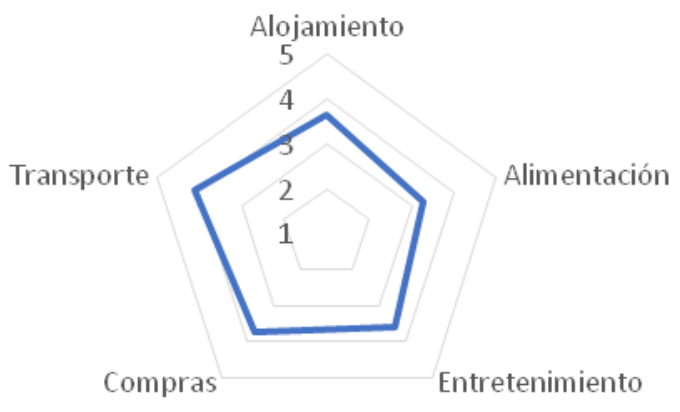

1.Muy caro 2. Caro 3. Ni caro, ni barato 4. Barato 5. Muy barato

Figura 11: Valoraciones acerca de los precios (2018).

Fuente. Elaboración propia. 
Referente los Destinos, motivos y experiencias de los que viajan a Manabí, predominantemente lo hacen con sus familiares (44\%). El alojamiento más seleccionado por los que pernoctan es hoteles $(42 \%)$, seguido de hostales $(26 \%)$ y casas de familiares y amigos (21\%) (figura 12).

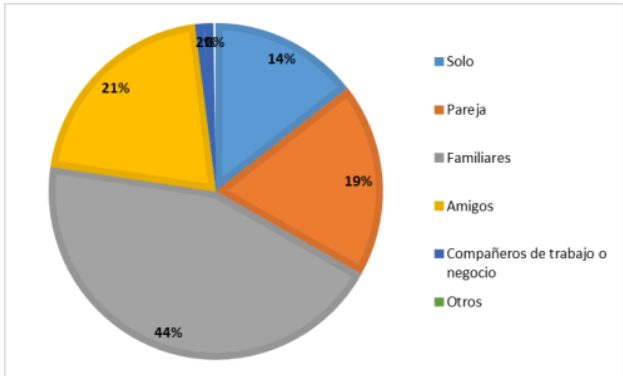

Acompañamiento en el viaje

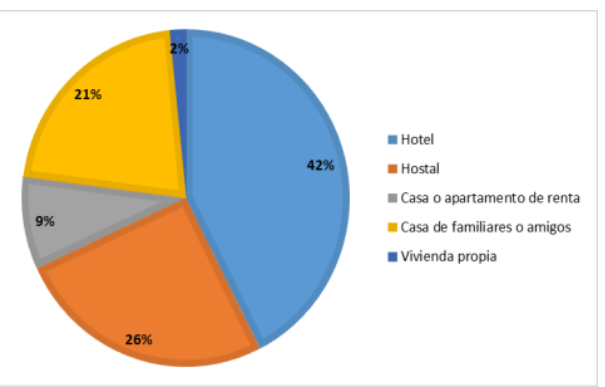

Tipo de alojamiento

Figura 12: Acompañamiento y alojamiento (2018)

Fuente: Elaboración propia.

El principal motivo de viaje a Manabí es vacaciones, recreo y ocio (73\%). De acuerdo con la encuesta, los visitantes que llegan a la provincia disfrutan del viaje y valoran la experiencia como muy buena (55\%) o buena (41\%) (figura 13$)$.

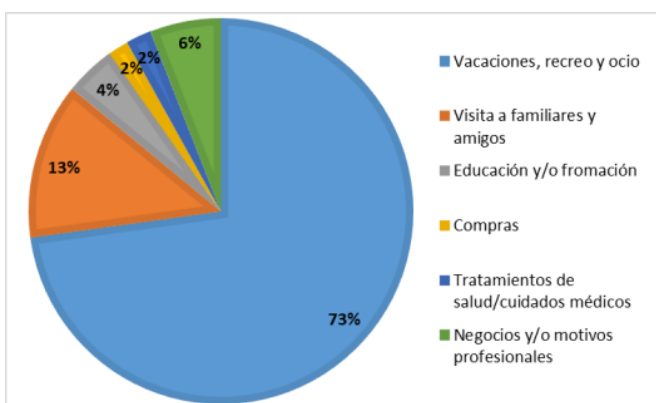

Motivos del viaje

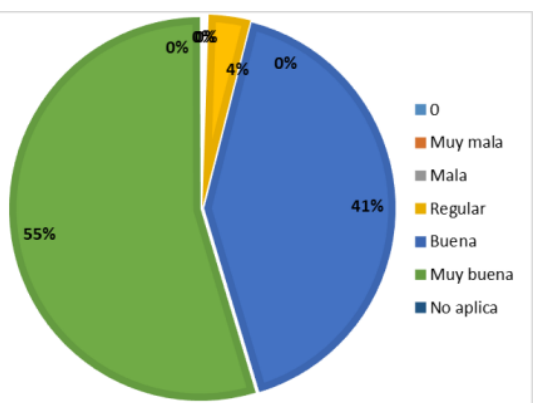

Valoración de la experiencia

Figura 13: Características principales de los motivos y experiencias (2018).

Fuente: Elaboración propia.

Las características del manabita, la diversidad de ofertas basadas en la riqueza geográfica natural y sociocultural, condicionan la satisfacción del visitante, aun con los problemas de calidad expresados en la figura 3.

\section{Operadores turísticos de la provincia Manabí}

Acerca del componente "operadores turísticos", la provincia de Manabí entre 2018 y 2020 contabilizó un promedio de 8.017 empleados en la actividad turística, lo que representó el 8,2\% del total del país (MINTUR, 2018a, 2019a, 2020). El análisis según cantones evidencia una clara concentración de empleo turístico en los cantones 
costeros, que son los que registran la mayor cantidad; entre ellos destacan Manta y Portoviejo, las principales ciudades económicas y comerciales de Manabí.

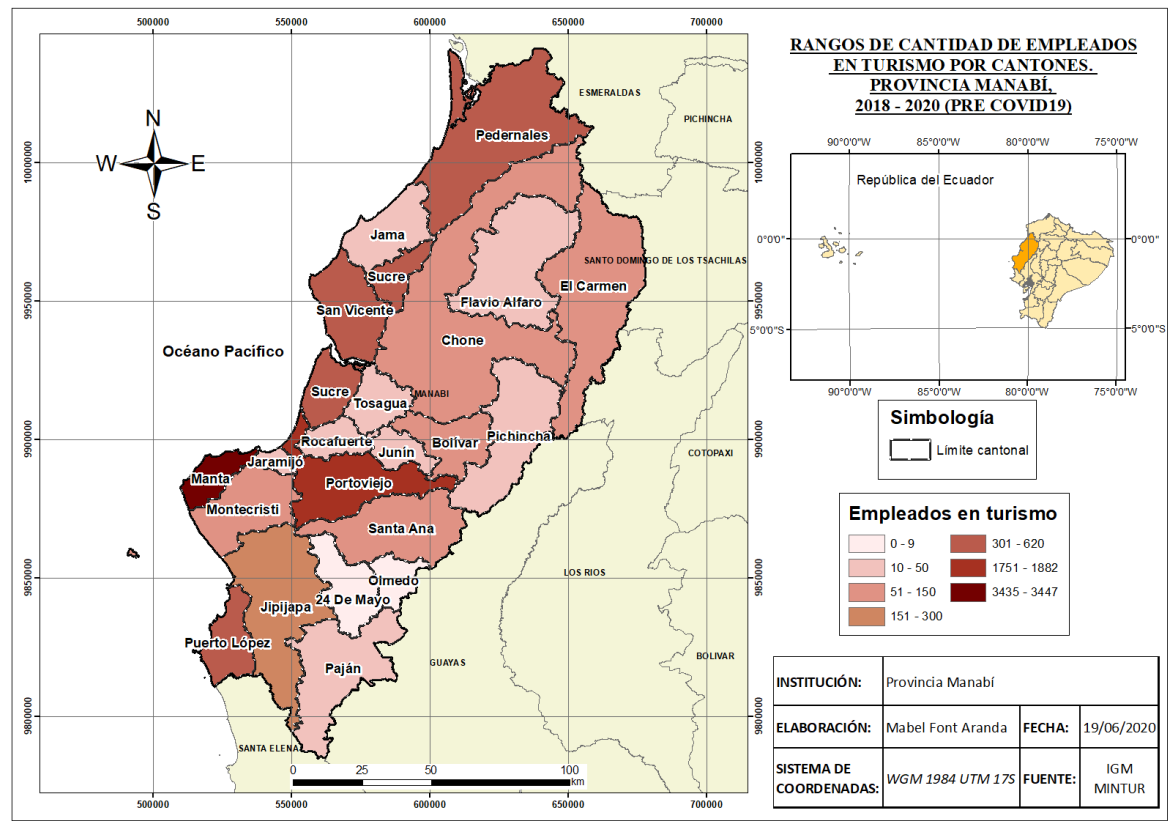

Figura 14: Empleados en turismo por cantones.

Fuente: Elaboración propia a partir de estadísticas del Mintur (2018 - 2020 marzo pre Covid19)

La estructura por género de los ocupados en turismo no muestra diferencias significativas de forma global, lo que representa una fortaleza. En la cantidad de ocupados por actividades turística destaca el sector de alimentos y bebidas, que ocupa el $60 \%$, seguido del de alojamiento (26\%). Estas dos actividades son las que más sobresalen, no solo en la provincia, sino también en el país (figura 14).

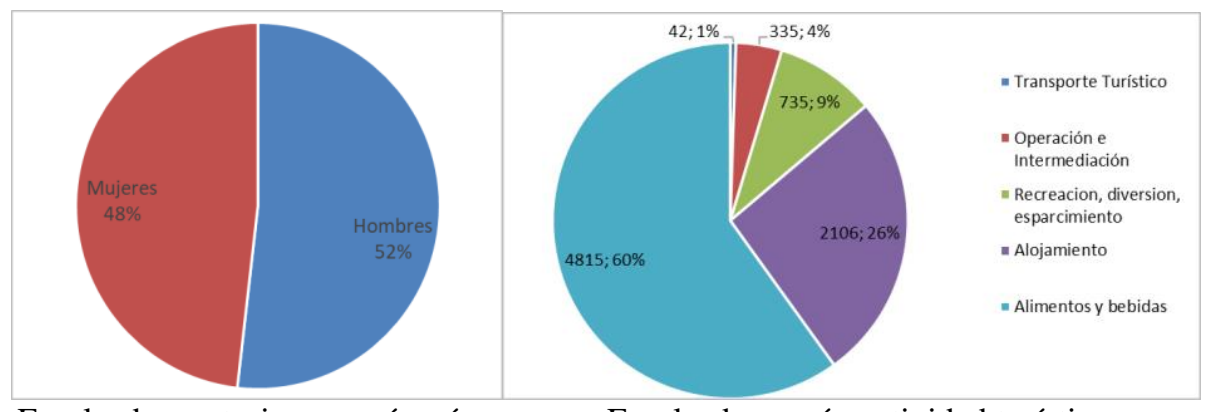

Empleados en turismo según género

Empleados según actividad turística

Figura 14: Estructura por géneros y actividades de los empleados en turismo.

Fuente: MINTUR, 2018 
En entrevista realizada al Ing. Isidro Antonio Rodríguez Lucas, servidor público Coordinador de Turismo Zonal 4. Manabí - Santo Domingo de los Tsáchilas (actualmente Director de Turismo del Gobierno Autónomo Descentralizado del cantón Manta) y con diez años de experiencia en el sector turístico Público, se han podido extraer las siguientes conclusiones:

1-Los propietarios de establecimientos no tienen una cultura de servicio desde una visión empresarial con sentido de pertenencia para brindar la excelencia. En base a los vacíos que tienen los dueños de negocios turísticos, se va creando una cadena que afecta la calidad del servicio, desde los propios colaboradores internos. Hay que fortalecer la preparación de los propietarios, de los empresarios, a quienes quieran poner un negocio; para que estén convencidos de que van a dar justamente servicios de calidad a la ciudadanía en correspondencia con las expectativas que tiene el usuario.

2- Muchos emprendimientos no han nacido de personas que han pasado un proceso de capacitación, si bien hay carreras en las universidades y en los institutos. Habría que declarar en las políticas públicas que todo tipo de operador de negocio incluya un porcentaje de recursos financieros para la incorporación de conocimientos básicos de lo que es la gestión de una empresa turística.

3- Se requiere el desarrollo de un modelo de negocio que considere la innovación para ser diferente a otro negocio, este aspecto no se tiene claro.

4- El trabajo en equipo es clave, no existe un eficaz proceso que considere todas las áreas. Si bien se han identificado algunos perfiles de ocupación en los establecimientos, muchas veces una persona hace varias tareas al mismo tiempo y se vuelve un poco complejo.

5- Falta de iniciativa del empresario en mejorar y acercarse a las instituciones públicas para poder ser parte de algún proceso participativo; invertir en sistemas de calidad u otros sistemas; no es frecuente.

Los resultados de la entrevista a los 40 gestores de la provincia se sintetizan y organizan en el diagrama de afinidad, de acuerdo a la importancia y coincidencia de criterios (figura 15). 


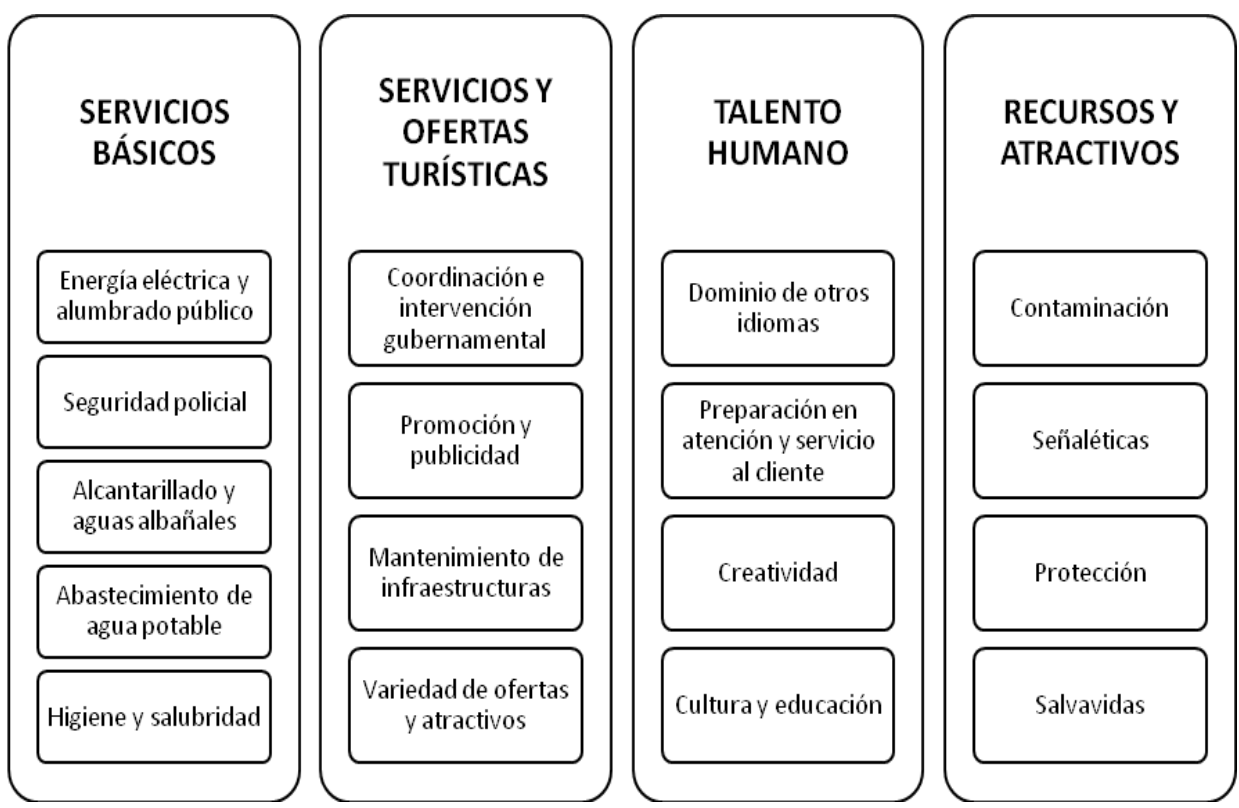

Figura 15: Diagrama de afinidad sobre áreas con problemas identificados por gestores turísticos de la provincia de Manabí.

Fuente: Elaboración propia.

Como muestra la figura 15 , los problemas prioritarios están relacionados con servicios básicos que sustentan todo el desarrollo de la actividad turística. En el estado actual de pandemia COVID-19, dicha situación empeora el panorama, requiriendo la solución de problemas ya existentes. La gestión de la oferta y servicios turísticos parte de la necesidad de coordinación desde la dirección cantonal. El autoanálisis sobre las falencias del talento humano es clave y muestra una preocupación consciente. Los gestores, aunque reconocen la variedad y riqueza de atractivos y recursos de la provincia, perciben falencias que hay que mejorar.

Los criterios entre gestores turísticos y la dirección de la actividad, aunque muestran coincidencias, revelan la falta de coordinación y alianzas entre los actores de la actividad turística provincial.

\section{Ejes claves de cambio para la calidad turística en la provincia Manabí}

Transitar hacia la gestión integrada e inteligente de destinos para la mejora homogénea de la calidad turística se expresa en un nuevo proyecto de transformación, aprobado por la Dirección de Investigación e Innovación Social y Tecnológica de la Universidad. En éste participan entidades públicas y privadas, se consideran las propuestas realizadas por los gestores del turismo, donde la universidad como institución aporta en el campo del enriquecimiento del talento humano y orienta en el desarrollo de otros proyectos de inversión y transformación empresarial y territorial por autogestión. 
Propuestas realizadas por el Coordinador de Turismo Zonal 4. Manabí - Santo Domingo de los Tsáchilas (Resultado de entrevista):

1- Aumentar los proyectos de parte del gobierno como ente rector, para motivar a los empresarios en poder asesorarse antes que inicie un negocio.

2- Vincular más la academia vincularse más con el mercado laboral y poner a las órdenes la oferta de profesionales.

3- Abrir la participación a los sistemas de calidad, que son muy interesantes, pero ahí está el reto de hacerlos participativo y que no se vean como un gasto sino, como una inversión.

4- Mantener la capacitación, debe ser constante, permanente con temas de innovación; el Ecuador tiene que dar un salto en este tipo de tema, para fortalecer la competitividad del establecimiento y del sitio como tal.

5-Fortalecer un programa universal en el país de manera colectiva, la deficiencia es el trabajo independiente sin alianzas y un trabajo colectivo a nivel macro.

Los gestores turísticos de la provincia proponen incidir en la mejora de las áreas identificadas con falencias y aclaman por la coordinación e intervención mancomunada con los Gobiernos Autónomos Descentralizados.

Todos los aspectos analizados avalan el desarrollo de una metodología que se proyecte a nivel local desde la empresa. Ello favorecerá la gestión integral de la calidad, que, incorporando la tecnología inteligente, y los sistemas de información geográfica; revelará los comportamientos espaciales y territoriales. La propuesta beneficiará la toma de decisiones por los actores, la elevación de la calidad de los servicios turísticos y el enriquecimiento de la experiencia de los turistas.

\section{Comentarios finales}

La realidad que vive el mundo ante la pandemia COVID-19, si bien ha alterado todo el equilibrio de la humanidad, sin duda ha dañado sobremanera el turismo, que ha sido de las actividades más afectadas. A pesar de esta realidad, las personas reanudarán los viajes, dados los vínculos sociales y económicos que caracterizan el mundo.

Lo antes planteado condiciona una pausa que obliga a los gobiernos y a los actores turísticos a replantearse alternativas para recuperar lo que antes fue el turismo. No obstante, solo se puede trascender al futuro y resolver el presente si se analiza el pasado y se rectifica en aquellas falencias que existían desde antes y que ahora obstaculizan más las soluciones.

La calidad en el ámbito turístico siempre ha tenido gran connotación, pues ella atraviesa todos los componentes del sistema turístico y es un factor determinante en la satisfacción del turista. España, en materia de gestión integral de la calidad y de destinos inteligentes, se ha destacado en la última década, y sus experiencias sirven de base para aplicar en otros contextos, aun en condiciones de subdesarrollo como ocurre en Ecuador. 
El análisis retrospectivo de la realidad turística en la provincia Manabí, Ecuador, revela que en condiciones de una diversidad geográfica natural, sociocultural y económica atractiva para los visitantes, existen problemas que, en el presente, complejizan el panorama. Reconocer tales deficiencias desde los componentes del sistema turístico permite afrontar con mayor precisión la interrupción obligada del desarrollo de esta actividad.

La investigación demuestra que la diversidad de los espacios turísticos de la provincia Manabí ha sido reconocida en los documentos oficiales del país y la provincia, por actores, gestores y turistas. De acuerdo con las encuestas realizadas, el $96 \%$ de las respuestas se asocia con la valoración de la experiencia como muy buena o buena y $37 \%$ de los que llegan a la provincia repiten el viaje; estas cifras indican un determinado nivel de satisfacción.

No obstante, se reconocen las deficiencias que existen en la provincia en el ámbito del turismo y de su gestión. A los problemas prioritarios identificados por PROAÑO y RAMÍREZ, (2017, p.71); SENPLADES, (2019, p.42) se le agregan otros identificados en esta investigación y que han sido visualizados por la máxima dirección y 40 gestores de los cantones turísticos de la provincia.

Los gestores declaran problemas prioritarios aquellos relacionados con servicios básicos que sostienen todo el resto de la actividad turística, la coordinación e intervención gubernamental, la promoción y publicidad y la autocomprensión de las limitantes que tienen como actores del turismo; estas son las áreas prioritarias por transformar.

El trabajo resume de forma global los ejes claves de cambio, el desarrollo de un proyecto dirigido a la aplicación de una metodología para la gestión integrada e inteligente de destinos turísticos en la provincia Manabí, que implique la vía inductiva de la participación voluntaria de empresarios, a través del entrenamiento por los entes universitarios y que tribute a la mejora homogénea de la calidad turística en el territorio.

Agradecimiento

A Fundación Carolina por el financiamiento para el desarrollo de esta investigación. A la Universidad de las Islas Baleares y a la Universidad Laica Eloy Alfaro de Manabí por facilitar el intercambio profesional. Al Dr. Mauricio Ruiz Pérez por la orientación en SIG.

\section{Referencias bibliográficas}

ÁLVAREZ GARCÍA J., DEL RÍO RAMA M., DURÁN SÁNCHEZ A., URBANO

ORGAZ B. Sistema de calidad turístico español: revisión de la literatura. Revista Ágora. Santa Cruz do Sul, v.19, n. 02, p. 04-13, jul./dez, 2017.

CORRAL-MARFIL, J. A. La implantación del sistema español de calidad turística en destinos (SICTED): un caso práctico de gestión de destinos. Revista TURyDES. Vol 5, № 13, (Diciembre/Dezembro 2012). 
DIRECCIÓN ZONAL 4 - Ministerio de Turismo. Catastro de establecimientos turísticos, Puerto López. Portoviejo. Ec. 2019

DOLAN, R., SEO, Y., \& KEMPER, J. Complaining practices on social media in tourism: A value co-creation and co-destruction perspective. Tourism Management, 73, 35-45. Doi:10.1016/j.tourman, 2019.

DURO, J.A Y RODRÍGUEZ, D. Barcelona como municipio turístico: algunos datos evolutivos y elementos de futuro. Documents d'Anàlisi Geogràfica X, vol. 61/3 507-538, 2015.

ECUADOR. Decreto Legislativo 0. Constitución de La Republica del Ecuador. (2008). Registro. Oficial 449 de 20-oct.-2008 Estado: Reformado. Ultima modificación: 01-ago.2018

ECUADOR. Ley 97. Ley de Turismo. Registro Oficial Suplemento 733 de 27-dic.-2002 Ultima modificación: 21-ago.-2018 Estado: Reformado Disponible en:

<https://www.turismo.gob.ec/wp-content/uploads/2019/02/2Ley-de-turismo-2018.pdf> Acceso en: 17 de octubre de 2019.

FONT ARANDA, M. y ÁLVARO SILVA, G. X. Concepción para el funcionamiento de un Observatorio Turístico en Manabí, Ecuador Revista Ibero-Americana de Estrategia - RIAE Rev. Iberoam. Estratég. São Paulo v.18 n.3, pp. 482-497, Jul-Set. 2019.

GAD - Gobierno Autómo Descentralizado de Puerto López. Catastro de establecimientos turísticos, Puerto López. Departamento de Turismo. Puerto López. Ec. 2019.

GOBIERNO ABIERTO DE ECUADOR. Disponible en: <https://gobiernoabierto.ec/> Acceso en: 18 de octubre de 2019.

GONZÁLEZ-MANSILLA, Ó.; BERENGUER-CONTRÍ, G.; \& SERRA-CANTALLOPS, A. The impact of value co-creation on hotel brand equity and customer satisfaction. Tourism Management, 75, 51-65. Doi:10.1016/j.tourman, 2019.

IGM - Instituto Geográfico Militar. Mapa físico de Ecuador y Mapa Político de Ecuador. Mapas del Ecuador (descargas). Disponible en:

<http://www.igm.gob.ec/work/files/downloads/mapafisico.html> Acceso en: 18 de octubre de 2019.

INEC - Instituto Nacional de Estadística y Censos. Proyecciones Poblacionales 2010 - 2020. Disponible en: <https://www.ecuadorencifras.gob.ec/proyecciones-poblacionales/> Acceso en: 18 de octubre de 2019.

IVARS-BAIDAL, J. A., \& VERA REBOLLO, J. F. Planificación turística en España. De los paradigmas tradicionales a los nuevos enfoques: planificación turística inteligente. Boletín de la Asociación de Geógrafos Españoles, 82, 2765, 1-31.

Http://dx.doi.org/10.21138/bage.2765. 2019,

MELLÉN MADRUGA C. Y SOLER REGLÍ M. Configuración de los nuevos Manuales de Buenas Prácticas. Metodología, Práctica y Plataforma. XV Foro SICTED. Valencia, 29 y 39 
de noviembre de 2018. P.12- Disponible en:

<https://www.calidadendestino.es/cadhandlers/download.file?ID=177651\&esdocumento=tru e> Acceso en: 18 de octubre de 2019.

MINISTERIO DE AMBIENTE Y AGUA. (2020). Sistema Nacional de áreas Protegidas del Ecuador. Disponible en <http://areasprotegidas.ambiente.gob.ec/mapa\#region-costa> Acceso en: 17 de octubre de 2019.

MINTUR - Ministerio de Turismo del Ecuador. Plan Nacional de Desarrollo de Ecuador. Plandetur 2020. Quito. Disponible en: <https://www.turismo.gob.ec/wpcontent/uploads/downloads/2013/02/PLANDETUR-2020.pdf> Acceso en: 17 de octubre de 2019.

MINTUR - Ministerio de Turismo del Ecuador. Catastro turístico de establecimientos a nivel nacional (Base de datos). Departamento de Investigación y Estadística. Quito. Ec. (2018a).

MINTUR - Ministerio de Turismo del Ecuador. Catastro turístico de establecimientos a nivel nacional (Base de datos). Departamento de Investigación y Estadística. Quito. Ec. (2019a).

MINTUR - Ministerio de Turismo del Ecuador. Plan de Desarrollo de Turismo 2030. Ministerio de Turismo del Ecuador - MINTUR. 2019b. Disponible en: <https://www.turismo.gob.ec/wp-content/uploads/2020/03/PLAN-NACIONAL-DETURISMO-2030-v.-final-Registro-Oficial-sumillado-comprimido_compressed.pdf> Acceso en: 18 de diciembre de 2019.

MINTUR - Ministerio de Turismo del Ecuador. Catastro turístico de establecimientos a nivel nacional (Base de datos actualizado marzo). Departamento de Investigación y Estadística. Quito. Ec. 2020.

NASA - EARTHDATA. ASTER Global Digital Elevation Model, Ecuador. U.S. Department of the Interior | U.S. Geological Survey. Disponible en: <https://gisgeography.com/free-global-dem-data-sources/> Acceso en: 29 de octubre de 2019.

OMT- Organización Mundial del Turismo. Manual práctico de gestión integral de la calidad de los destinos turísticos - Conceptos, implementación y herramientas para autoridades, instituciones y gestores de destinos, OMT, Madrid. ISBN: 978-92-844-1684-4, 2015.

OMT- Organización Mundial del Turismo. Directrices de la OMT para el fortalecimiento de las organizaciones de gestión de destinos (OGD) - Preparando las OGD de cara a nuevos retos, OMT, Madrid, DOI: https://doi.org/10.18111/9789284420933, 2019.

OMT- Organización Mundial del Turismo. Barómetro del Turismo Mundial. Publicado e impreso por la Organización Mundial del Turismo. ISSN: 1728-9254. Madrid (España) Primera edición, 2020. Volume 18, Issue 1, January, 2020.

PADDISON, B., \& BIGGINS, R. Advocating community integrated destination marketing planning in heritage destinations: The case of york. Journal of Marketing Management, 33(910), 835-857. Doi:10.1080/0267257X.2017.1329226. 2017. 
PARASURAMAN, A., ZEITHAML, V. A., \& BERRY, L. L. SERVQUAL: a multiple-item scale for measuring consumer perceptions of service quality. Journal of Retailing, 64(1), 12 40. 1988.

PEARCE, D. G. Toward an Integrative Conceptual Framework of Destinations. Journal of Travel Research, Vol. 53(2) 141 -153. Doi:10.1177/0047287513491334, 2014.

PROAÑO PONCE, W. P. Y RAMÍREZ PÉREZ, J. F. (2017). Modelo de Desarrollo Turístico Sostenible para cantones costeros: herramienta para actores locales de Manabí, Ecuador Revista Posgrado y Sociedad. Sistema de Estudios de Posgrado. Universidad Estatal a Distancia. ISSN: 2215-2172 Volumen 15, Número 2, 65-78. PP. 72, 2017.

PULIDO-FERNÁNDEZ, J. I., \& LÓPEZ-SÁNCHEZ, Y. La cadena de valor del destino como herramienta innovadora para el análisis de la sostenibilidad de las políticas turísticas. El caso de España. Innovar, 26(59), 155-176. Doi: 10.15446/innovar. v26n59.54369. 2016.

SANCHO, A. Y OTROS. Introducción al Turismo. OMT. Disponible en https://0-www-e-unwto-org.llull.uib.es/doi/pdf/10.18111/9789284402694. 1998.

SECRETARÍA DE ESTADO DE TURISMO- ESPAÑA. (2019). ¿Qué es el SICTED? Sistema Integral de Calidad Turística en Destinos. Octubre de 2019 Ministerio de Industria, Energía y Turismo. Licencia: Creative Commons Reconocimiento 2.0 España. Madrid. Disponible en:

<https://www.calidadendestino.es/documentos/2019_1003_Que_es_el_SICTED.pdf> Acceso en: 27 de octubre de 2019.

SENPLADES - Secretaria Nacional de Planificación y Desarrollo. Agenda Zonal. Zona 4Pacífico. Manabí Santo Domingo de los Tsáchilas (2013- 2017). SENPLADES Ediecuatorial/ 1 edición - Quito, Ecuador. 2015.

SENPLADES - Secretaria Nacional de Planificación y Desarrollo. Plan Nacional de Desarrollo 2017-2021. Toda una Vida. Edición - Quito - Ecuador. 2017. Disponible en: <https://www.planificacion.gob.ec/wp-content/uploads/downloads/2017/10/PNBV-26-OCTFINAL_0K.compressed1.pdf>_Acceso en: 18 de octubre de 2019.

SENPLADES - Secretaria Nacional de Planificación y Desarrollo. Agendas Zonales. Zona 4 Pacífico, Manabí - Santo Domingo de los Tsáchilas (2017-2021). Primera Edición, 2019. Senplades, abril 2019. Manta, Ecuador. Disponible en: 〈https://www.planificacion.gob.ec〉 Acceso en: 25 de octubre de 2019.

SWISSCONTACT. Conceptos básicos para la Gestión de Destinos Turísticos. Lima: Arkabas, 2014.

SU, L., SWANSON, S. R., \& CHEN, X. (2016). The effects of perceived service quality on repurchase intentions and subjective well-being of chinese tourists: The mediating role of relationship quality. Tourism Management, 52, 82-95. Doi:10.1016/j.tourman, 2016. 
Mabel Font Aranda

Doctor en Ciencias Geográfica por la Universidad de La Habana de Cuba, Master en Gestión Turística por la Universidad de Matanzas de Cuba, Postdoctorado en Gestión integrada e inteligente de destinos turísticos y sistemas de información geográfica por la Universidad de las Islas Baleares - Fundación Carolina. Actualmente es Profesora Titular Principal y Líder de Proyecto de la Facultad de Hotelería y Turismo de la Universidad Laica Eloy Alfaro de Manabí, Ecuador.

Email: mabel.font@uleam.edu.ec

\section{Joana María Petrus Bey}

Doctor en Geografía por la Universidad de las Islas Baleares. Actualmente es Profesora Titular de Universidad de Análisis Geográfico Regional y Vicedecana de la Facultad de Filosofía y Letras de la Universidad de las Islas Baleares, España. Es coordinadora de los Programas de Movilidad e Intercambio de la Facultad de Filosofía y Letras y Tutora del Programa de Becas de Estancias Cortas Postdoctorales de Fundación Carolina.

Email: joana.petrus@uib.es

Recebido para publicação em setembro de 2020. Aprovado para publicação em março de 2021. 